\title{
ARTICLE
}

\section{Study on criticality in natural barrier for disposal of fuel debris from Fukushima Daiichi NPS}

\author{
Taro Shimada*, Kazuya Takubo, Seiji Takeda and Tetsuji Yamaguchi \\ Japan Atomic Energy Agency, 2-4 Shirakata, Tokai-mura, Naka-gun, Ibaraki-ken, 319-1195, Japan
}

\begin{abstract}
After fuel debris is removed from the reactor containment vessel at Fukushima Daiichi NPS (1F) and collected in containers in the future, the containers may be disposed of at a deep geological repository. The uranium inventory and fissile $U$ enrichment of the fuel debris can be higher than those of spent fuels and high-level vitrified wastes. In this study, we estimated the quantity of uranium precipitated at the natural barrier using one-dimensional migration analysis, and studied dimension of uranium precipitated in the natural barrier and carried out the criticality analysis. As the result, more than $200 \mathrm{MTU}$ is precipitated at redox front in the natural barrier to reach the criticality. Criticality analysis indicated that $k_{\text {eff }}$ is lower than 0.98 when all uranium of $250 \mathrm{MTU}$ distributed into longer than $700 \mathrm{~m}$ as cuboid shape at the accumulated area.
\end{abstract}

Keywords: Fukushima Daiichi NPS; fuel debris; criticality in natural barrier; nuclides migration; fissile $U$ enrichment; uranium

\section{Introduction}

After fuel debris is removed from the reactor containment vessel at Fukushima Daiichi NPS (1F) and collected in containers in the future, the containers may be disposed at a deep geological repository. The total uranium inventory of unit one to three was $257 \mathrm{MTU}[1]$. Average burnup of fuels in the middle of reactor operation is lower than that of spent fuels. The average ${ }^{235} \mathrm{U}$ enrichment of the fuel debris is approximately $2 \%$ which is higher than that of the spent fuel and the high-level vitrified wastes (HLW). For the disposal of the spent fuel and the HLW, it had been indicated that appropriate engineering of the waste form and the repository can reduce any remaining probability of criticality in the natural barrier [2,3]. On the other hand, we cannot exclude the possibility that a criticality occurs in the geological media where the uranium from the fuel debris precipitates after the uranium in the repository is dissolved and transported by groundwater. If criticality occurs at the natural barrier, mobile fission products are generated and heat is also produced by fission reactions, promoting migration to the biosphere.

Liu et al. calculated effective neutron multiplication factors for a sphere of uranium from the fuel debris precipitated in sandstones with the range less than $30 \%$ porosity under the condition of fissile $U\left({ }^{235} U\right.$ and $\left.{ }^{233} U\right)$ enrichment of $2.25 \%$ [4]. They indicated that only 0.63 MTU of the uranium can reach criticality if it forms a spherical deposition in which volume fraction of uranium and water are $9.5 \%$ and $20.5 \%$, respectively. Generally, the repository is situated in a reducing environment to minimize the corrosion of the overpack

*Corresponding author. Email: shimada.taro@jaea.go.jp and the dissolution of radionuclides in the waste form to the groundwater, and to facilitate sorption of radionuclides onto the rocks. However, there is a possibility that the reducing environment will be changed to oxidizing in the long-term and the solubility of the uranium will be several orders of magnitude larger. It will promote the dissolution and migration of uranium. In this study, we estimated the quantity of uranium precipitated at the natural barrier, focusing on one-dimensional radionuclides migration with consideration of the chemical environment. Furthermore, we carried out criticality analysis reflecting the three-dimensional shape of uranium precipitated in the natural barrier, of which quantity and enrichment were calculated above.

\section{Method of radionuclide migration analysis}

In order to investigate the quantity of uranium accumulated in the natural barrier, radionuclides migration analysis from repository to an area in the natural barrier was carried out for waste containers containing fuel debris. Table 1 shows the total radioactive inventory of the fuel debris as of 50 years after the accident [1]. The number of the containers was assumed to be 4,193 by reference to TMI- 2 storage containers [5]. The repository was assumed to be the same as geological disposal where the container covered with an overpack and a bentonite buffer with $70 \mathrm{~cm}$ of thickness is situated at a disposal galley in the natural barrier consisting of sedimentary rocks [6]. The one-dimensional migration analysis code of GSRW-PSA [7], which had assumed no precipitation in the natural barrier, was modified so that it can evaluate the 
Table 1. Total radioactive inventory of fuel debris for typical radionuclides.

\begin{tabular}{cccccccccc}
\hline Nuclide & mol & Nuclide & mol & Nuclide & mol & Nuclide & mol & Nuclide & mol \\
\hline${ }^{233} \mathrm{U}$ & $5.74 \times 10^{-3}$ & ${ }^{236} \mathrm{U}$ & $3.51 \times 10^{3}$ & ${ }^{238} \mathrm{Pu}$ & $7.27 \times 10^{1}$ & ${ }^{241} \mathrm{Pu}$ & $8.04 \times 10^{1}$ & ${ }^{243} \mathrm{Am}$ & $4.63 \times 10^{1}$ \\
${ }^{234} \mathrm{U}$ & $4.09 \times 10^{1}$ & ${ }^{238} \mathrm{U}$ & $1.02 \times 10^{6}$ & ${ }^{239} \mathrm{Pu}$ & $4.82 \times 10^{3}$ & ${ }^{242} \mathrm{Pu}$ & $2.99 \times 10^{2}$ & ${ }^{245} \mathrm{Cm}$ & $6.16 \times 10^{-1}$ \\
${ }^{235} \mathrm{U}$ & $1.91 \times 10^{4}$ & ${ }^{237} \mathrm{~Np}$ & $3.30 \times 10^{2}$ & ${ }^{240} \mathrm{Pu}$ & $1.62 \times 10^{3}$ & ${ }^{241} \mathrm{Am}$ & $8.15 \times 10^{2}$ & ${ }^{246} \mathrm{Cm}$ & $5.50 \times 10^{-2}$ \\
\hline
\end{tabular}

Table 2. Calculation cases.

\begin{tabular}{|c|c|c|c|c|c|}
\hline \multirow[b]{2}{*}{ Case No. } & \multirow{2}{*}{$\begin{array}{l}\text { Dissolution rate } \\
(1 / y)\end{array}$} & \multirow{2}{*}{$\begin{array}{l}\text { Chemical environment } \\
\text { in engineered barrier }\end{array}$} & \multicolumn{2}{|c|}{ U solubility $(\mathrm{mol} / \mathrm{L})$} & \multirow{2}{*}{$\begin{array}{c}\text { Migration } \\
\text { distance in natural } \\
\text { barrier }(\mathrm{m})\end{array}$} \\
\hline & & & Engineered barrier & $\begin{array}{l}\text { Area of accumulation } \\
\text { in natural barrier }\end{array}$ & \\
\hline Case 1 & $1 \times 10^{-7}$ & Reducing & $3.1 \times 10^{-6}$ & $1.1 \times 10^{-5}$ & 100 \\
\hline Case 2 & $1 \times 10^{-7}$ & Oxidizing & 5.0 & $1.1 \times 10^{-5}$ & 100 \\
\hline Case 3 & $1 \times 10^{-7}$ & $\begin{array}{l}\text { Reducing to oxidizing } \\
\text { after } 10^{5} \text { years }\end{array}$ & $3.1 \times 10^{-6}$ to 5.0 & $1.1 \times 10^{-5}$ & 100 \\
\hline Case 4 & $1 \times 10^{-7}$ & Oxidizing & 5.0 & $1.1 \times 10^{-5}$ & 1000 \\
\hline Case 5 & $1 \times 10^{-6}$ & Reducing & $3.1 \times 10^{-6}$ & $1.1 \times 10^{-5}$ & 100 \\
\hline Case 6 & $1 \times 10^{-7}$ & Reducing & $3.1 \times 10^{-6}$ & $1.1 \times 10^{-7}$ & 100 \\
\hline Case 7 & $1 \times 10^{-7}$ & Reducing & $3.1 \times 10^{-5}$ & $1.1 \times 10^{-5}$ & 100 \\
\hline
\end{tabular}

precipitation by connecting a new compartment dealing with solubility limit to the migration path in the natural barrier.

Table 2 shows the calculation cases. Case 1 is a standard reducing environment for geological disposal. Cases 2 and 3 are assuming cases for oxidizing environment. Cases 4 to 7 consider the uncertainty of dissolution rate, migration distance and solubilities at the engineered barrier and the area of accumulation in the natural barrier. Dissolution rate of fuel debris in the standard case was determined based on that of spent fuel $[8,9]$. Actual groundwater velocity was set to $3.3 \times 10^{-4}$ $\mathrm{m} / \mathrm{y}$ in the natural barrier with reference to the example of sedimentary rock site [10] and $4.5 \times 10^{-4} \mathrm{~m} / \mathrm{y}$ in the bentonite buffer. Table $\mathbf{3}$ shows the chemical compostion of groundwater and porewater for both reducing and oxidizing environment $[11,12]$.

Table 4 shows the solubility and distribution coefficient $(K d)$ of the elements that may influence the criticality. The solubility was calculated by PA-SOL code using chemical compositions of groundwater for reducing and oxidizing environments [13]. The values were also set based on the chemical composition of groundwater. Diffusion coefficients were set to $8.4 \times 10^{-4}$ $\mathrm{m}^{2} / \mathrm{y}$ for the bentonite buffer and $3.2 \times 10^{-2} \mathrm{~m}^{2} / \mathrm{y}$ for the natural barrier.

\section{Results from radionuclide migration analysis}

\subsection{Influence of redox conditions}

Figure 1 shows the calculation results of the amount of accumulated uranium. Significant accumulation of uranium is not observed in Cases 1 and 5 in which the solubility is higher at the area of accumulation than in the engineered barrier.

In cases 2, 3, 6 and 7 on the other hand, more than 10 tons of uranium is precipitated at the area of accumulation because of the drastic decrease of the $U$ solubility. In cases 2, 3 and 7, accumulated uranium reaches 66.1 MTU at $2 \times 10^{8}$ years after the closure of the repository. Maximum uranium deposition, $211 \mathrm{MTU}$, is observed after $5 \times 10^{8}$ years in case 6 where the solubility
Table 3. Chemical composition of each water type.

\begin{tabular}{cccc}
\hline & $\begin{array}{c}\text { Groundwater } \\
\text { Reducing }\end{array}$ & $\begin{array}{c}\text { Porewater } \\
\text { Reducing }\end{array}$ & $\begin{array}{c}\text { Porewater } \\
\text { Oxidizing }\end{array}$ \\
\hline $\mathrm{pH}$ & 6.8 & 10.0 & 6.0 \\
$\mathrm{pe}$ & -3.6 & -10.0 & 3.38 \\
$\mathrm{Al}$ & $1.9 \times 10^{-7}$ & $7.1 \times 10^{-7}$ & $1.9 \times 10^{-7}$ \\
$\mathrm{C}$ & $5.0 \times 10^{-3}$ & $8.9 \times 10^{-2}$ & $4.0 \times 10^{-4}$ \\
$\mathrm{Ca}$ & $2.8 \times 10^{-3}$ & $1.2 \times 10^{-3}$ & $1.0 \times 10^{-4}$ \\
$\mathrm{Cl}$ & $8.8 \times 10^{-2}$ & $6.6 \times 10^{-2}$ & $5.3 \times 10^{-4}$ \\
$\mathrm{Fe}$ & $6.0 \times 10^{-5}$ & $1.2 \times 10^{-9}$ & $5.4 \times 10^{-7}$ \\
$\mathrm{~K}$ & $2.6 \times 10^{-3}$ & $7.9 \times 10^{-3}$ & $8.2 \times 10^{-5}$ \\
$\mathrm{Mg}$ & $2.5 \times 10^{-3}$ & $6.3 \times 10^{-8}$ & $9.9 \times 10^{-5}$ \\
$\mathrm{Na}$ & $1.1 \times 10^{-1}$ & $6.5 \times 10^{-2}$ & $6.9 \times 10^{-4}$ \\
$\mathrm{~S}$ & $8.1 \times 10^{-5}$ & $5.1 \times 10^{-3}$ & $9.8 \times 10^{-5}$ \\
$\mathrm{Si}$ & $3.9 \times 10^{-4}$ & $3.3 \times 10^{-3}$ & $3.6 \times 10^{-4}$ \\
\hline
\end{tabular}

Elements concentration: $\mathrm{mol} / \mathrm{L}$

Table 4. Solubility and distribution coefficient of the elements.

\begin{tabular}{|c|c|c|c|c|c|}
\hline & \multicolumn{3}{|c|}{ Engineered barrier } & \multicolumn{2}{|c|}{$\begin{array}{l}\text { Area of accumulation } \\
\text { in natural barrier }\end{array}$} \\
\hline & \multicolumn{2}{|c|}{ Solubility $(\mathrm{mol} / \mathrm{L})$} & \multirow{2}{*}{$\begin{array}{c}K d \\
\left(\mathrm{~m}^{3} / \mathrm{kg}\right)\end{array}$} & \multirow{2}{*}{$\begin{array}{c}\text { Solubility } \\
(\mathrm{mol} / \mathrm{L})\end{array}$} & \multirow{2}{*}{$\begin{array}{c}K d \\
\left(\mathrm{~m}^{3} / \mathrm{kg}\right)\end{array}$} \\
\hline & Reducing & Oxidizing & & & \\
\hline $\mathrm{U}$ & - & - & 1 & - & 0.07 \\
\hline $\mathrm{Np}$ & $9.8 \times 10^{-7}$ & $6.2 \times 10^{-4}$ & 1 & $6.2 \times 10^{-6}$ & 0.07 \\
\hline $\mathrm{Pu}$ & $2.7 \times 10^{-8}$ & $3.3 \times 10^{-8}$ & 1 & $1.5 \times 10^{-3}$ & 0.07 \\
\hline Am & $4.4 \times 10^{-5}$ & 0.65 & 10 & $3.3 \times 10^{-2}$ & 80 \\
\hline $\mathrm{Cm}$ & $4.4 \times 10^{-5}$ & 0.65 & 10 & $3.3 \times 10^{-2}$ & 80 \\
\hline
\end{tabular}

of uranium at the area of accumulation is assumed two orders of magnitude lower than the standard value.

Case 4 yields only a small amount of deposition under the condition of ten times longer migration distance because ${ }^{235} \mathrm{U}$ decays out before reaching the area of accumulation.

Figure 2 shows temporal change of the enrichment of fissile uranium transported from the repositories and precipitated at the area. The maximum value of precipitated uranium is $2.25 \%$ in case 2 and 3 . However, the enrichment decreases to approximately $2.0 \%$ when accumulated uranium reaches the peak of 66.1 MTU. In case 6 , the enrichment decreases to $1.6 \%$ when accumulated uranium reaches the peak of $211 \mathrm{MTU}$. In case 5, the enrichment reaches approximately 4\% because dissolved ${ }^{237} \mathrm{~Np}$ which decays to ${ }^{233} \mathrm{U}$ is more than that in other cases due to higher dissolution rate of 
the fuel debris, when the quantity of accumulated uranium is less than $10^{-6}$ MTU.

The calculation results indicate that a typical situation for accumulation of a large quantity of uranium is that the oxidizing groundwater dissolves uranium from the repository, and dissolved uranium is transported and precipitated at the redox front far from the repository as shown in Figure 3. In order to keep the redox front in the long term, continuous flow of oxidizing and reducing groundwater into an area of accumulation is required.

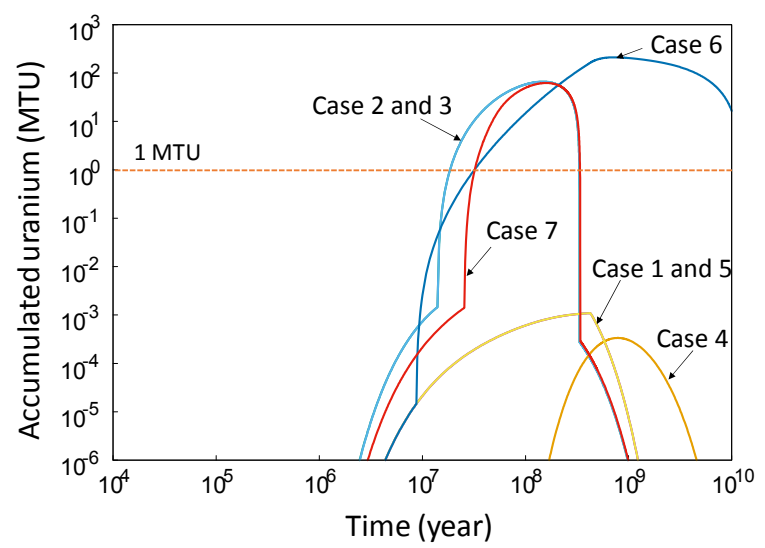

Figure 1. Temporal change of the amount of accumulated uranium.

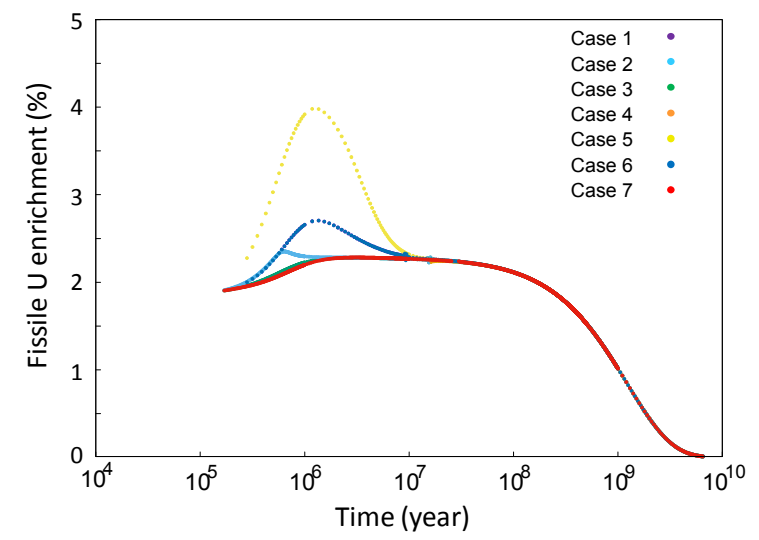

Figure 2. Temporal change of fissile uranium enrichment of the accumulated uranium at the area.

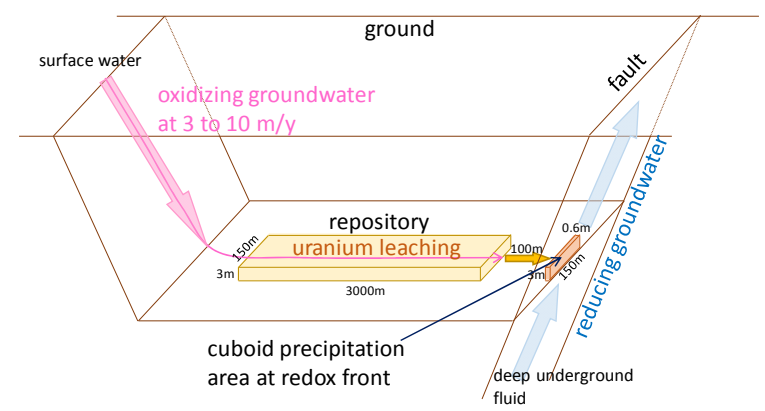

Figure 3. A Typical situation for accumulation of a large quantity of uranium by change of chemical environment.

\subsection{Influence of groundwater velocity}

Actual groundwater velocity was set to $3.3 \times 10^{-4} \mathrm{~m} / \mathrm{y}$ as a constant value for the calculation above. However, the uranium concentration in the groundwater depends on the velocity. The influence of the groundwater velocity on the quantity of accumulated uranium was analyzed.

\subsubsection{Influence on uranium concentration in groundwater}

Based on the calculation conditions of case 2 as a standard case, actual groundwater velocity was changed from $3.3 \times 10^{-4} \mathrm{~m} / \mathrm{y}$ to $17 \mathrm{~m} / \mathrm{y}$. Figure 4 shows the quantity of accumulated uranium. When the velocity is an order of magnitude larger than the standard case, the quantity of accumulated uranium is increased to 212 MTU. When the velocity is larger than $10 \mathrm{~m} / \mathrm{y}$, the amount of uranium accumulated is smaller than 1 MTU. As shown in Figure 5, the uranium concentration does not reach the solubility limit for the velocity faster than $10 \mathrm{~m} / \mathrm{y}$.

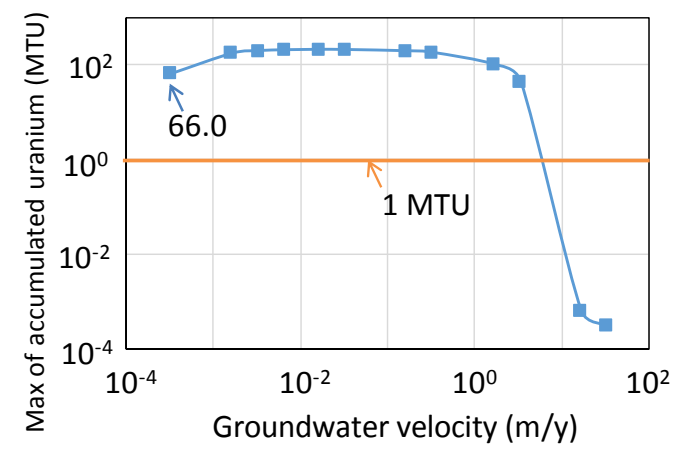

Figure 4. Accumulated uranium corresponding to actual groundwater velocity.

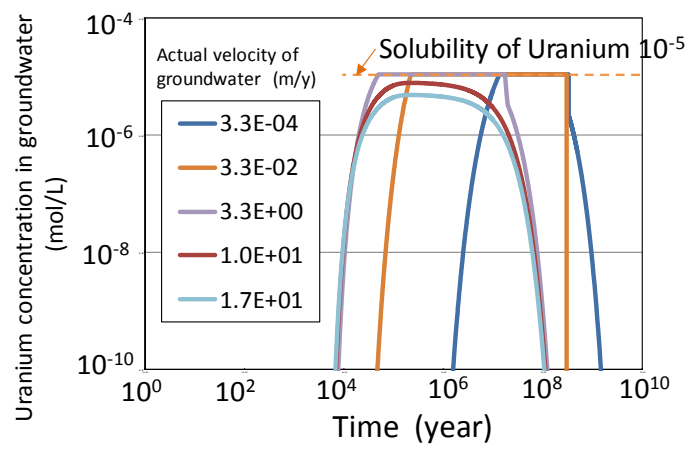

Figure 5. Uranium concentration in groundwater at the accumulated area corresponding to the velocity.

\subsubsection{Advection prevailing system}

Because diffusion decreases concentration gradients of solute, accumulation of materials never occurs in diffusion prevailing systems. Advection should prevail over diffusion in order to realize the accumulation of uranium and also to perpetuate the redox front. The Peclet number, $v L / D e$ should be more than unity. The groundwater velocity should be higher than $3.2 \mathrm{~m} / \mathrm{y}$ assuming the characteristic length $L=0.01 \mathrm{~m}$ and the diffusivity coefficient $D e=3.2 \times 10^{-2} \mathrm{~m}^{2} / \mathrm{y}$. Therefore, actual groundwater velocity should be from 3 to $10 \mathrm{~m} / \mathrm{y}$ 
to reach criticality. It is difficult for the criticality to occur because the velocity around the repository is usually much lower than $0.1 \mathrm{~m} / \mathrm{y}$ for a candidate site for geological disposal.

\section{Criticality analysis}

Although Liu et al. used only a spherical model in the criticality analysis [4], a cube shape model is used in this study assuming that uranium leached from the repository accumulates downstream in a cubic area with a height of $3 \mathrm{~m}$ as shown in Figure 1. The quantity of accumulated uranium and the enrichment of fissile uranium were assumed to be $250 \mathrm{MTU}$ and $2.25 \%$, respectively based on the results of the above one-dimensional migration analysis. Other parameters were the same as those used by Liu et al. in the fractured system I with an aperture $b=1 \mathrm{~cm}$ [4]. The 250 MTU occupies $274 \mathrm{~m}^{3}$ assuming the occupation of $9.5 \%$ and density of $9.6 \mathrm{ton} / \mathrm{m}^{3}$. Some results of the criticality analysis were shown in Table 5 .

When a side of cuboid in accumulated area is less than $150 \mathrm{~m}$ long and more than $0.6 \mathrm{~m}$ wide, $k_{\text {eff }}$ exceeds 1.0 and the criticality occurs. The $k_{\text {eff }}$ for the dimension of $200 \mathrm{~m}$ long, $3.0 \mathrm{~m}$ high and $0.45 \mathrm{~m}$ wide is 0.98 , which remains subcritical in the natural barrier. The critical conditions can be described by geometrical buckling $B_{g}{ }^{2}$ defined as:

$$
B_{g}^{2}=\left(\frac{\pi}{L}\right)^{2}+\left(\frac{\pi}{H}\right)^{2}+\left(\frac{\pi}{W}\right)^{2}
$$

where $\mathrm{L}, \mathrm{H}$ and $\mathrm{W}$ are length, height and width of the cuboid, respectively, and $\mathrm{L} \times \mathrm{H} \times \mathrm{W}$ equals $274 \mathrm{~m}^{3}$. When $B_{g}{ }^{2}$ is higher than 48.46 , the $k_{\text {eff }}$ is below 0.98 , namely subcritical.

When the length is longer than $700 \mathrm{~m}, B_{g}{ }^{2}$ cannot be lower than 48.46, which means subcritical. The length on a side of the repository of geological disposal of HLW is around $3 \mathrm{~km} \mathrm{[6].} \mathrm{As} \mathrm{the} \mathrm{number} \mathrm{of} \mathrm{the} \mathrm{fuel}$ debris containers, 4,139 is an order of magnitude lower than 40,000 of vitrified wastes of HLW and the area for a repository is also smaller than that for HLW, the length of a side of the repository for the fuel debris is assumed to be approximately $900 \mathrm{~m}$.

Table 5. Calculation results of $\mathrm{k}_{\text {eff }}$ for some typical dimensions.

\begin{tabular}{cccccc}
\hline Case & $\mathrm{L}(\mathrm{m})$ & $\mathrm{H}(\mathrm{m})$ & $\mathrm{W}(\mathrm{m})$ & $\mathrm{k}_{\text {eff }}$ & $\mathrm{B}_{\mathrm{g}}{ }^{2}$ \\
\hline $\mathrm{A}$ & 100 & 3.0 & 0.9 & 1.079 & 12.94 \\
$\mathrm{~B}$ & 150 & 3.0 & 0.6 & 1.027 & 27.74 \\
$\mathrm{C}$ & 200 & 3.0 & 0.45 & 0.980 & 48.46 \\
\hline
\end{tabular}

\section{Conclusion}

A possibility that uranium dissolved at the repository migrates in the natural barrier and more than $200 \mathrm{MTU}$ is accumulated at redox front to reach criticality in the natural barrier for disposal of the $1 \mathrm{~F}$ fuel debris was indicated by the one-dimensional migration analysis. Criticality analysis on a cuboid geometry of $250 \mathrm{MTU}$ with fissile $U$ enrichment of $2.25 \%$ occupying $9.5 \%$ in the sandstone media with $30 \%$ porosity showed that it is consistently subcritical when all uranium is distributed into more than $700 \mathrm{~m}$ in the accumulated area.

\section{Acknowledgements}

This research is funded by the Secretariat of Nuclear Regulation Authority, Nuclear Regulation Authority, Japan. Dr. Logan D. Barr of JAEA is acknowledged for improvement of the English.

\section{References}

[1] K. Nishihara et al., Estimation of Fuel Compositions in Fukushima-Daiichi Nuclear Power Plant. JAEA-Data/Code 2012-018, Japan Atomic Energy Agency, (2012).

[2] W. E. Kastenberg et al., Considerations of Autocatalytic criticality of fissile materials in geologic repositories, Nucl. Technol. 115 (1996), pp. 298-310.

[3] J. Ahn et al., A preliminary consideration for underground autocatalytic criticality by vitrified high-level waste in water-saturated geologic repository, J. Nucl. Sci. Technol. 37 (2000), pp.465-476.

[4] X. Liu et al., Conditions for criticality by uranium deposition in water-saturated geological formations, J. Nucl. Sci. Technol. 52 (2015), pp.416-425.

[5] U.S. Department of Energy Assistant Secretary for Environmental Management Office of Nuclear Material and Spent Fuel, TMI Fuel Characteristics for Disposal Criticality Analysis, DOE/SNF/REP-084, (2003).

[6] JNC, H12: Project to Establish the Scientific and Technical Basis for HLW Disposal in Japan, JNC TN1410 2000-001, Japan Nuclear Cycle Development Institute, (2000).

[7] S. Takeda et al., Assessment on Long-term Safety for Geological Disposal of High Level Radioactive Waste, JAEA-Research 2009-034, Japan Atomic Energy Agency, (2009). [in Japanese]

[8] JAEA, Preliminary Assessment of Geological Disposal System for Spent Fuel in Japan - First Progress Report on Direct Disposal, Japan Atomic Energy Agency, JAEA-Research 2015-016, (2015). [in Japanese]

[9] T. Shimada et al., Sensitivity Analysis on Safety Functions of Engineered and Natural Barriers for Fuel Debris Disposal, MRS Advances, 2 (2017), pp. 687-692.

[10]T. Shimada et al., Analysis of radionuclide migration with consideration of spatial and temporal change of migration parameters due to uplift and denudation, MRS proceedings, 1744 (2015), pp.229-234.

[11]T. Kunimaru et al., Analysis ground water from boreholes, river water and precipitation in the underground research laboratory project, Japan 
Atomic Energy Agency, JAEA-Data/Code 2007-015, (2007). [in Japanese]

[12]T. Hokari, Estimation of dominant in situ redox reactions of groundwaters and hot springs in Japan, J. Hot Spring Sci., 62, (2012). pp.225-236. [in Japanese]
[13]T. Yamaguchi et al., An attempt to select thermodynamic data and to evaluate the solubility of radioelements with uncertainty under HLW disposal conditions, Radiochim. Acta 2014; 102 (2014), pp.999-1008. 